\title{
ARTICLE
}

\section{The Unbalanced Equation: Technical Opportunities and Social Barriers in the NAE Grand Challenges and Beyond}

\author{
Dean Nieusma* and Xiaofeng Tang ${ }^{\dagger}$ \\ Department of Science and Technology Studies, Rensselaer Polytechnic Institute \\ * nieusma@rpi.edu, + tangx3@rpi.edu
}

The US National Academy of Engineering's 2008 report, Grand Challenges for Engineering, puts forward a provocative vision of future civilization and engineering's role in it. Notably, the report signals a trend in engineering toward more explicit and direct engagement with enduring, complex social problems, offering intriguing opportunities for exploring the relationship between engineering and questions of social justice. This paper makes one such exploration by analyzing the report's explicit framings of engineering-for-social-problem-solving and the implicit assumptions underlying such framings. It shows how the report frames the non-technical factors as external to-and often barriers for-engineering. In contrast, technical challenges, even immense ones, are framed as wholly within engineering's dominion and as opportunities for both engineering and human civilization as a whole. The paper argues that Grand Challenges signals contemporary tensions in the profession as it seeks an expansive domain of influence and relevance while at the same time narrowly circumscribing what engineers should be accountable for knowing and doing.

KEYWORDS: boundary work, Grand Challenges, interdisciplinary collaboration, National Academy of Engineering, sociotechnical practice, technical-social division, textual analysis

\section{INTRODUCTION}

In 2008, the US National Academy of Engineering (NAE) released its report, Grand Challenges for Engineering, which describes 14 major engineering challenges that must be overcome to make the world "a more sustainable, safe, healthy, and joyous-in other words, better-place" (p. 6). These challenges encompass areas as diverse as energy, the environment, infrastructure, human health, security, learning, and research, but in each case the emphasis is on what are articulated as the "engineering" dimensions of the larger problem domain and, in particular, on the technologies and tools that might enable solutions to evident, often enduring challenges facing contemporary civilization.

Since its publication, the report has drawn significant attention from the engineering community and has been the subject of two national summits, Obama Administration initiatives, and STEM education programs, both $\mathrm{K}-12$ and university. ${ }^{1}$ Industry leaders also have been eager to

1 The second national NAE Grand Challenges Summit was held in Los Angeles, 6-8 October 2010. The White House Office of Science and Technology Policy and the National Economic Council announced a request for information on Grand Challenges on 21 September 2009. NAE Grand Challenge K12 Partners Program was launched "[t]o create an awareness of and involvement in the NAE Grand Challenges for the K12 community." A number of universities have joined the NAE Grand Challenge Scholars Program to prepare the next generation of engineers for solving grand-challenge problems. 
demonstrate the connection between their activities and the grand challenges, such as IBM's Big Green Initiative, which claims to address a number of challenges identified in the NAE report. ${ }^{2}$

Given this attention, and the general enthusiasm with which it has been received, the NAE Grand Challenges for Engineering report (hereafter Grand Challenges) offers an intriguing opportunity to reflect on how engineers imagine what engineering is and what its proper role in society ought to be, including how it relates with questions of social justice. This paper contributes one such reflection, carefully analyzing Grand Challenges as a way to interrogate broader social and cultural meanings surrounding engineering, technology, and their relationships to major social and environmental problems. We argue that, in important respects, Grand Challenges relies on a problematic and increasingly outdated understanding of engineering as distinct and apart from the social contexts in which it is practiced. In other words, the report endorses a conception of engineering that is "purely technical" at its foundation. As we will show, this conception undermines the goal of shifting engineering, as a whole, toward social problem solving by misconstruing critical attributes of both the social problems being addressed and the technologies intended to solve them. ${ }^{3}$

Certainly, we are sympathetic to the impulse underlying the report, namely to direct engineering energies toward "the century's great challenges" (p. 6), with the derivative social-justice goals of addressing the needs of the impoverished, ameliorating ecological decay, and enhancing the ability of people everywhere to participate meaningfully in social life. Despite these sympathies, our analysis identifies key assumptions embedded in Grand Challenges that are likely to constrain efforts to develop robust solutions to complex social problems in ways that enhance social justice.

In this paper, our approach to social justice follows a body of emerging literature on engineering and social justice (Baillie, 2006; Catalano, 2007; Leydens, Lucena, \& Schneider, 2012; Riley, 2008). To advance social justice through engineering, we emphasize two dimensions of engineering competency that combine ethical stances and cognitive capabilities. The first dimension involves comprehension of the broad (social) context of engineering work and candid reflection on the role of engineering and engineers in social change (Jamison, Christensen, \& Botin 2011). The second dimension calls for engineers' critical engagement with political forces in order to advance the interests of marginalized social groups through collaborative sociotechnical action (Downey, 2009). We argue that maintaining a social-technical dichotomy in engineering thinking-as evident throughout Grand Challenges-impairs engineers' ability to engage the contextual complexities impinging on their work and, further, alienates non-engineering stakeholders with whom engineers ought to be collaborating.

In identifying and describing problematic approaches taken in Grand Challenges, our purpose is not merely to offer a detached, academic critique. Instead, we are motivated by a desire to reframe

\footnotetext{
2 To see how industry leaders discuss grand challenges as business opportunities, see the blog entry "You need to think of each of these grand challenges as a business."

3 Various facets of the social/technical divide in engineering have been extensively examined in engineering studies. Faulkner (2000) inquires into the gendered nature of the social-technical dualism in engineering. Lagesen and Sørensen (2009) suggest two sets of reasons for the continuous maintenance of the social/technical binary in engineering: one represents the attempt of retaining the "scientific" nature of engineering knowledge while it addresses social issues; the other stems from engineers' justification of its professional privilege. Cech and Waidzunus (2011) suggest the social/technical dualism excuses engineers from discussing hard social problems within the profession. Our analysis of the social/technical divide in the Grand Challenges report intends to reveal a gap between engineers' attempt to maintain professional privilege and the practical needs of fully addressing social challenges.
} 
"engineering" in ways that make it more amenable to social problem solving and to help engineering decision makers more productively engage the various social forces influencing their work. Hence, after working through some of the most problematic assumptions and approaches evident in Grand Challenges, we then propose alternative understandings of engineering that are more in line with the complexities of the grand-challenge problems and that more readily align with social justice initiatives. These alternative understandings synthesize insights being developed within the engineering studies community-and within science and technology studies (STS) more broadly-over the past few decades. In our assessment, these understandings promise more imaginative engineering approaches and more robust contributions to social justice.

\section{Methodology}

The paper is based on a textual analysis of Grand Challenges in light of recent work in engineering studies and STS. Our approach "views texts as symbolic action, or means to frame a situation, define it, grant it meaning, and mobilize appropriate responses to it" (Manning \& Cullum-Swan, 1994, p. 465). We focus attention on how and where the authors of the report demarcate "engineering" from that which is external to engineering but which engineers must respond to nevertheless. In particular, we investigate how the authors characterize engineering activities and knowledge versus how they characterize those forces impinging upon engineering from the outside. ${ }^{4}$ As indicated above, we take the report as representative of one dominant way engineering and its relationships to its various (social) contexts are understood, both inside and outside the engineering community; however, we do not include those larger contexts in our analysis. ${ }^{5}$ Because the empirical material and our institutional home situate this analysis in the US, our arguments apply particularly to the US context. Nevertheless, we hope and expect many of the insights gained apply elsewhere as well. While Grand Challenges provides the primary empirical material of our analysis, we also draw comparisons between Grand Challenges and the prior NAE report, The Engineer of 2020 (2004).

By "textual analysis" of Grand Challenges, we refer to an interpretative method that explores the rhetorical and conceptual terrain of the report text itself as opposed to how meaning making around the report varies in specific social contexts. Our process entailed four basic steps:

1) Close reading of the report;

2) Identification of sentences and phrases that address the engineering/non-engineering boundary or engineering's relationship to non-engineering factors, including various dimensions of social-problem solving;

3) Coding of the text using categories that spanned and connected these articulations; and

4) Iterating the categorization scheme to create a delimited set of themes that captured most of the identified articulations.

The first three steps were carried out independently and in parallel by each of the authors, and the fourth step was carried out in collaboration, in part by merging our individual findings. ${ }^{6}$ After

\footnotetext{
${ }^{4}$ In STS, the practice of negotiating what is inside and what is outside a given category is called boundary work. See Geiryn (1983) for a classic analysis of how scientists demarcate science from non-science.

5 We acknowledge the limitations of our approach in that the content of Grand Challenges is a social production derived from particular social and organizational arrangements and inflected by strategic goals, which we do not systematically explore. Yet, insofar as the Grand Challenges report is the authors' articulation of how engineering ought to be, and not simply a transparent statement of what it is, there is value in characterizing and unpacking the idealized vision of engineering as portrayed therein.

${ }^{6}$ We did not deliberately follow any particular textual analysis method (e.g., Foucaultian discourse analysis, Saussurian semiotics), but our analysis was framed by a social-constructivist framework and theoretical insights from STS and Engineering Studies around boundary work and the technical-social binary.
} 
refining our themes, we referred to The Engineer of 2020 to clarify and highlight alternative articulations about engineering and its context, and how these alternatives might offer a more promising vision for reorienting engineering to grand-challenge problem solving and social justice.

The Grand Challenges text is significant and deserving of systematic attention for two reasons. First, it resonates strongly with participants in engineering, engineering policy making, and engineering education as evidenced by its uptake, dissemination, and frequent referencing in these communities. The approach taken in Grand Challenges clearly aligns with the perspective taken by a wide and influential audience interested in engineering, education, and their reform. Second, the report's authors disproportionately represent corporate and research institutions (numbering 15, with 3 exceptions-one journalist, one politician, and one development banker), suggesting that it provides mostly an "internalist" account of engineering. As an internalist account, the perspective provided is from that of (particularly situated) practicing engineers and emphasis is placed on the variables within those persons' primary domain of influence. Given this perspective, perhaps it is not surprising to see a more-or-less neat demarcation between technical opportunities and social barriers; however, this neat demarcation makes challenging the assumptions underlying it even more important to explore. Hence, while the scope of our empirical material is narrow, we believe the implications of our analysis are broad.

\section{“Engineering" in Grand Challenges: The TeChNicAl-SOCIAL Divide}

The Grand Challenges report puts forward an image of engineering that is gallant, perhaps even heroic. The report opens: "Throughout human history, engineering has driven the advance of civilization" (NAE, 2008, 1). It later adds that engineering brings together "the rules of reason, the findings of science, the aesthetics of art, and the spark of creative imagination" and has "revolutionized and improved virtually every aspect of human life" (p. 2). The veracity of such generalized claims is impossible to determine, and, besides, this particular vision of engineering serves in the report mostly as a set-up for the big challenges ahead. Nevertheless, from its first sentence, Grand Challenges frames engineering as a domain of achievement and mastery, as having tried-and-true techniques for solving big problems, and as already ready for the challenges ahead.

Perhaps not surprising in a report of this type, Grand Challenges also characterizes engineering in a way that may be inspiring for the uninitiated but is otherwise problematic. The boundary between engineering and other disciplinary or professional realms is inconsistently applied and strategically played across the report. Grand Challenges identifies humanity's great achievements as engineering achievements, even where the connection is tenuous (e.g., the taming of fire. p. 2). At the same time, it leaves totally unaddressed engineering's contributions to social and ecological problems, including its contributions to some of the central problems underlying the grand challenges themselves.

After surveying great achievements of engineering, the report continues: "For all of these [engineering] advances, though, the century ahead poses challenges as formidable as any from millennia past" (p. 2). It then goes on to frame those problems as inevitable byproducts of civilization's progress (e.g., caused by population growth, consumer demand, etc.) rather than unintended consequences of intended human actions-including engineering problem solving. For example, as the report celebrates engineering's contribution to agriculture, it is silent about engineering's contribution to creating the synthetic fertilizers that disrupt the natural nitrogen cycle. As the report salutes the great achievement of the automobile, it is silent about automobiles' contribution to the grand challenges associated with excessive energy consumption and urban 
congestion. Even the grand-challenge problems of controlling carbon emissions and preventing nuclear terror are disassociated from their engineering origins.

In a similar vein, Grand Challenges is silent about the need to anticipate unintended consequences of the technological solutions proposed for the 14 grand challenges identified. For example, the report claims that providing energy from fusion has a lot of advantages, including its inherent safety (unlike with fission, run-away reactions are not possible with fusion). Other reasonable safety concerns-like waste management and effluents ${ }^{7}$-are left unaddressed. Hence, the report ignores unintended negative consequences of engineering solutions in the past as well as the future.

We draw attention to these silences in the report not to suggest that the solution paths identified by the Grand Challenges authors are inappropriate, but instead to highlight the double standard applied to social and technical facets of engineering throughout the report: While engineering is cast as responsible for advancing civilization (a social phenomenon, to be sure), it is not also seen to be responsible for any ills resulting from engineered systems. While engineers should be prideful of the social benefits of the technologies they collectively have devised, there is no need, implied by the report, to hold engineering accountable for the social detriments of those very same technologies. Far from being part of the problem, a "technocratic" approach to engineering remains our best solution. ${ }^{8}$

Although the report's authors claim not to have endorsed any particular approach to addressing the grand challenges identified, in fact a very particular approach to problem solving is offered. This approach takes existing engineering problem-solving techniques as sufficient (if not inevitable); it subsumes all the good associated with technological advance under "engineering" and externalizes or ignores the bad; and it puts forward narrowly technical solution paths to the complex social problems underlying each of the grand challenges. By reducing complex social phenomena to narrow technical problems amenable to traditional engineering training, Grand Challenges limits engineers' responsibilities to their existing, narrow technical expertise. Simultaneously, the report externalizes responsibility for the ("social") barriers that prevent or slow the creation of engineering solutions. This understanding of engineering-as merely offering tools that others misuse-is historically dominant to be sure, connected centrally to the mainstay argument that technology is neutral (Pitt, 1999). But as with the neutrality argument, the dominance of the Grand Challenges approach to engineering does not mean it is inevitable or even desirable. ${ }^{9}$

The Grand Challenges report's asymmetrical treatment of technology-with the benefits of technology attributed to engineering and the liabilities to other factors-reflects a crucial assumption that carries across the report, namely, that technology challenges can be neatly separated into technical and social factors. Technical factors include various means of increasing efficiencies, refining processes, and facilitating basic scientific research. Such means, the report implies, are the best (perhaps the only) way engineers might go about addressing grand-challenge problems. Just as engineering is understood narrowly around technical factors, so too are broader

\footnotetext{
${ }^{7}$ Studies have shown that dust particles in nuclear fusion may pose a safety threat (Sharpe, Petti, \& Bartels, 2002; Winter 2000).

8 Put simply, technocracy represents a decision-making process that prioritizes narrow technical criteria, and hence technical experts, in pursuing social goals. Early work on technocracy is Veblen (1921). Layton (1986) and Akin (1977), among others, have examined the history of technocratic movements in the US.

${ }^{9}$ Social scientists in general, and STS scholars in particular, have contended the belief that technology is neutral. They have shown that some technological developments necessarily call for engineers' value choices and their usage is inextricably entwined with certain patterns of political arrangement (Winner, 1988).
} 
social factors understood (narrowly) as external to, but impinging on, engineering. Such an understanding is conveyed in this telling claim: "governmental and institutional, political and economic, and personal and social barriers will repeatedly arise to impede the pursuit of solutions to problems" (NAE, 2008, p. 6). With the occasional exception of economic factors (particularly, costs), Grand Challenges articulates organizational, political, and cultural factors both as outside engineering and as "barriers" to be overcome wherever they exist in tension with achieving narrowly specified technical goals.

\section{Defining Engineering as Technical Problem Solving}

The technical-social division is especially problematic in how Grand Challenges translates complex sociotechnical challenges into narrowly technical challenges and then suggests that existing technologies or engineering developments currently on the horizon are capable of solving these technical challenges. An example of such a reductive interpretation of grand challenges is the discussion about personal learning. The report starts by drawing attention to individual differences in learning and stating that existing educational approaches lack flexibility in meeting individual needs. While this set-up hints at the importance of addressing different learning styles, personalities, motivations, and so on-in other words, looking at the full complexity of the challenge of individualized education-the report then turns abruptly toward a specific, narrow technical sub-problem: optimizing learning outcomes by manipulating the sequence in which materials are presented to students. To achieve this radically narrowed goal, the report introduces a solution: a computer algorithm that "eliminates unsuccessful presentation sequences and modifies successful ones for a new round of tests, in which the least successful are again eliminated and the best are modified once more" (NAE, 2008, p. 46).

As most thoughtful educators recognize, sequencing of material is a minor variable in the larger equation of successful (individualized) learning. What material is included, how materials are connected to students' existing knowledge and experiences, and the dynamics of the learning environment are all widely recognized as more significant than the ordering of content alone. ${ }^{10}$ As with most other examples, the particular solution offered and the (radically) narrowed technical problem it "solves" are perfectly acceptable as far as they go, but they do not go far enough. Individual learning differences demand attention to a wide set of pedagogical and curricular variables, and devising solutions to this larger problem requires both an appreciation of the problem's complexity as well as an understanding that optimizing any given approach does not substitute for the arguably more important judgment about what approach ought to be used to begin with.

Extending from the theme of social justice are questions surrounding the purpose and roles of education and the institutional and economic contexts in which education takes place. Without considering the "higher purposes" of education, for example, the report says nothing about how the computerized learning model proposed might facilitate critical thinking, commitment to the educational process, empathy for others, lifelong learning, or student ability to identify and solve problems for themselves. The report is also silent about structural problems surrounding the current American educational system in particular, such as the lack of qualified and dedicated teachers, the under-representation of minority groups in higher education, waning interest in STEM

\footnotetext{
${ }^{10}$ See, e.g., Eberly Center for Teaching Excellence's "Teaching Principles." Also see Freire's (1996) classical work on the power dynamics of education. Psychological literature on college students' epistemological development also stresses the importance of metacognition in learning (Baxter Magolda, 1992; Belenky, Clinchy, Goldberger, \& Tarule, 1986; Hofer \& Pintrich, 2002; King \& Kitchener, 1994; Perry, 1970).
} 
fields, etc. ${ }^{11}$ By abstracting the proposed technical solution from the larger social context of education, Grand Challenges identifies one potentially relevant research agenda, certainly, but not one that addresses anywhere near the complexity of the initially stated problem.

By stripping away the social and political context of big social problems, Grand Challenges not only oversimplifies the nature of the challenges; it also fails to encourage engineers to assume prominent roles in collaborations initiated outside narrow technical realms. The report's approach to the challenge of providing clean water and basic sanitation in developing countries showcases such a miss. Whereas water is a scarce resource in many places in the developing world, the problems of consistent supply of clean water and sanitation services raise much broader questions than water purification or desalination systems alone can answer. Questions about infrastructure installation, health-care management, public investment, and ownership and use rights surrounding water resources are all essential components of the water and sanitation problems faced by poor communities globally (Gopakumar, 2010). To be fair, the report does recognize political and economic facets of the challenge of water provision, such as the prevalence of inequities in distributing water resources. Yet it limits the engineering-relevant focus to desalination, distillation, and purification technologies alone.

The solar energy challenge is another example of where the report reduces a complex and largely uncertain problem (making solar energy systems affordable) into specific technical indexes. In this example, Grand Challenges implies the necessary techniques are already in hand; the need is merely to continue refining (and ramping up investment in) developments already well along. The report discusses in detail the prospect for new technologies' increased efficiency in transferring solar energy to usable forms, as if promising solutions to the solar challenge merely await technical implementation. Despite the report's emphasis on efficiency in this section, the connotation of the term "efficiency" here is vague and mercurial. The report discusses, in turn, the energy conversion efficiency of commercial solar cells, the theoretical maximum efficiency of current standard cells, new materials and experimental cells, and the theoretical efficiency of yet-to-be-deployed nanocrystal-based systems. Apart from these imagined theoretical data, the report does not explain the net-gains of each solar energy project, the overall costs per unit energy generation and delivery, or the political landscape that shapes America's renewables energy policy (e.g., Obama Administration support for such policies on the affirmative side and fossil-fuel lobbyists on the negative).

Clearly, we question the sensibility and viability of delimiting engineering along technical dimensions alone. That said, we do not question the sensibility or viability of narrowly technical expertise within engineering. To the contrary, we believe narrowly technical skills are both essential and essentially desirable, but only so in a broader understanding of engineering that spans both technical and social domains.

\section{The Role of Non-Technical Participants in Grand-Challenge Problem Solving}

The translation of complex sociotechnical challenges into narrow technical ones has implications for how engineers understand their relationships with other stakeholders. Grand Challenges extends its conceptual separation of technical and social factors to the division of labor between engineers and other practitioners. Engineers (along with scientists) are put forward as ideal role models for advancing grand-challenge solutions; other social and professional groups are frequently cast as impediments, either resistant to or not adequately supporting the technical

11 Maria Klawe identifies these same problems in a recent talk given at the 2010 NAE Grand Challenges National Summit. 
solutions offered by engineers. The role of participants outside of technoscientific disciplines, according to the approach taken in Grand Challenges, is merely to facilitate scientific and technical progress. The report occasionally recognizes the necessity of engineers communicating with nonengineering groups in dealing with the non-technical aspects of engineering problem solving, but that is only to facilitate or otherwise enable technical research and development. Ultimately, it is engineers who possess the requisite technical expertise. Therefore, it is they who should play the primary role in tackling the grand challenges.

Grand Challenges characterizes the role to be played by non-engineers as one of deference. The report highlights that the public image of engineering is not always congruent with engineers' selfunderstanding, and it attributes the incongruence to public ignorance of engineering and inappropriate if not irrational resistance to technological innovation. An implicit agenda of Grand Challenges seems to be enhancing the authority of engineers, increasing trust in engineering, and developing within society-at-large "an appreciation of the ways that scientists and engineers acquire the knowledge and tools required to meet society's needs" (NAE, 2008, p. 5). As the report states in its introduction:

\begin{abstract}
The ultimate users of engineering's products are people with individual and personal concerns, and in many cases, resistance to new ways of doing things will have to be overcome. Teachers must revamp their curricula and teaching styles to benefit from electronic methods of personalized learning. Doctors and hospital personnel will have to alter their methods to make use of health informatics systems and implement personalized medicine. New systems for drug regulation and approval will be needed when medicines are designed for small numbers of individuals rather than patient populations as a whole. (NAE, 2008, p. 5)
\end{abstract}

In each of these cases, the new technologies are assumed to be superior to existing approaches and to be linchpins in addressing the underlying (social) problem. Non-technical practitioners in each domain are cast not as collaborators in problem solving or even as resources to be drawn on by engineers, but merely as potential nodes of resistance. ${ }^{12}$

The ideal relationship between engineers and scientists is more ambiguous in Grand Challenges. On one hand, engineers frequently legitimize their expertise with the authority of scientific knowledge, or even view engineering as "applied science" (Kline, 1995). Hence, scientists are viewed as natural allies. At the beginning of the report, the authors characterize engineering as "[a]pplying the rules of reason, the findings of science, the aesthetics of art, and the spark of creative imagination" (NAE, 2008, p. 2). But throughout the report, engineers are paired regularly only with scientists: "In the century ahead, engineers will continue to be partners with scientists in the great quest for understanding many unanswered questions of nature" (p. 48). On the other hand, Grand Challenges distinguishes engineers' unique contributions to society, even in the domain of scientific knowledge production: "In the popular mind, scientists and engineers have distinct job descriptions. Scientists explore, experiment, and discover; engineers create, design, and build. But in truth, the distinction is blurry, and engineers participate in the scientific process of discovery in many ways" (p. 48). Here again, the report plays the boundaries of engineering loosely, in this case the boundary between science and engineering, to cast engineering in its most favorable light. 13

\footnotetext{
12 Engineers' distrust of the public has a long history, with evidence dating back at least to the technocracy movement of the early 1900s. At that time, technocrats-many of whom were engineers-typically framed the public as a barrier to the social realignments demanded by technical rationality (Akin 1977).

${ }^{13}$ Some engineers have argued that engineering is an autonomous body of knowledge independent of science (Vincenti, 1990).
} 
The tension created by engineers' ambiguous relationship with scientists represents an opportunity for engineers to embrace more collaborative and interdisciplinary inquiry into evermore complicated sociotechnical challenges. As engineers seek to expand their roles in what are traditionally considered arenas for scientists, architects, doctors, educators, or even policy makers, they are bound to question and redefine the scope of engineering as an enterprise, and Grand Challenges offers opportunities for engineering to be understood in a way that includes factors beyond the technical. For example, the report repeatedly points out that contextual matters (e.g., the material, political, or organizational infrastructure surrounding water and sanitation solutions or computer security protocols) are important in specifying technical solutions. The report also occasionally emphasizes that synergy across a number of interconnected fields is needed to tackle certain types of challenges, but even here the emphasis is placed on technoscientific dimensions of problems. For example, the report suggests that personalized medicine "will be addressed by the collaborative efforts of researchers from many disciplines, from geneticists to clinical specialists to engineers" (NAE, 2008, p. 31). These openings point the way toward a more expansive understanding of engineering and its potential contributions to grand-challenge problems, but the report does not follow through with such an approach.

\section{Alternative Framings: Beyond the Social-TeChnical Divide}

Contrary to the approach taken in Grand Challenges, we argue that effectively responding to the social injustices surrounding grand-challenge problems requires rethinking engineering-both what it is understood to be and how it is practiced. This section draws on an additional NAE publication, The Engineer of 2020, in an effort to identify understandings to engineering that do not rely so heavily on the problematic assumptions described above.

Instead of unquestioned confidence in the sufficiency of current or emerging technologies in responding to grand challenges, we argue that acknowledging uncertainties is an essential starting point. Such uncertainties exist both with our understandings of the problems being addressed and with the engineering solutions to be applied. The Engineer of 2020 adopted such a stance in stating: "The particular factors that will dominate engineering practice and require reform of engineering education are not predictable" (NAE, 2004, p. 59). According to this vision of an uncertain future, conventional problem-solving techniques may well be inadequate for tackling the intricate challenges facing humanity today. Additionally, some of the problems that will confront engineers in the future are certain to be unknown in the present. A more realistic alternative for mapping out the future is to admit that neither engineers nor others can be certain about the variables that will shape the future and to focus instead on developing strategies for coping with uncertainties. ${ }^{14}$ Nowhere in Grand Challenges do we see a call for engineers to direct their energy towards better monitoring of current "solutions" or on-going analysis of grand-challenge-type problems as they arise and evolve. In what is perhaps an ironic twist, the idealized narrowly-technical approach to engineering offered by Grand Challenges would be incapable even of adequately discerning the problems put forward by the report as grand challenges, given that they arise and exist beyond the boundaries of technical engineering.

\footnotetext{
14 Science and technology policy scholars have advocated shifting away from approaches that attempt to eliminate uncertainties through systematic analysis and toward approaches that accept uncertainty in scientific and technological outcomes as inevitable. According to this approach, effort should be directed at identifying strategies for coping with unintended outcomes as they come to light over time (Lindblom \& Woodhouse, 1993, Ch 2; Woodhouse \& Nieusma, 2001).
} 
In comparison to Grand Challenges, The Engineer of 2020 seeks to explore new roles of engineering and engineers in a changed context. As an entry point, The Engineer of 2020 identifies one unchanged feature of what is otherwise an ever-changing future: the interconnection between engineering and society. It states, "The future is uncertain. However, one thing is clear: engineering will not operate in a vacuum separate from society in 2020 any more than it does now" (NAE, 2004, p. 27). The remainder of this section explores three dimensions of this enduring feature of engineering by elaborating ways engineering knowledge and practice are inevitably entwined with "the social." First, we consider the marginalization of the social in engineering and offer a more integrated model. Then, we look at engineering practice and how engineers might be more productive (in terms of grand-challenge problem solving) by collaborating on more diverse teams. Third, we propose a more reflective and critical stance toward engineering by engineers in order to promote a more realistic and balanced appreciation for what can and cannot be achieved under the model of engineering put forward in Grand Challenges.

\section{Engineering as Sociotechnical Practice}

The Engineer of 2020 takes a decidedly different stance than Grand Challenges on the relationship between the technical and social dimensions of engineering. Rather than considering political, organizational, and cultural concerns as external or barriers to approaching important engineering challenges, it sees these as always existing alongside technical dimensions of engineering practice. 15 According to the report, "it is not just the nature of a narrow technical challenge but the legal, market, political, etc., landscape and constraints that will characterize the way the challenge is addressed" (NAE, 2004, p. 35). As a result, confronting complex engineering challenges, such as updating and securing information and communication infrastructure, as suggested by the report, "will clearly involve legal, regulatory, economic, business, and social considerations" (p. 20). It is worth noting that, according to The Engineer of 2020, social considerations are not simply minor variables that happen to intersect with engineering practice. Rather, "consideration of social issues is central to engineering" (p. 27). In this understanding, engineering is "sociotechnical" practice, where social and technical dimensions interpenetrate through and through.

The Engineer of 2020 does not suggest that this integrated approach to engineering should be created from whole cloth. Because engineers are comfortable with "systems analysis," the report urges them to extend the scope of the "systems" they already consider within their domain, specifically by including facets of social systems alongside the technical. To do this, engineers will have to enrich their existing expertise with better understandings of public policy and community needs as well as enhanced social and political acumen. While experts in other domains undoubtedly have roles to play in fleshing out our understandings of sociotechnical systems, engineers share responsibility for integrating diverse insights into a coherent model. They also share responsibility for, ultimately, achieving synergy between technical and social dimensions of any given system. Such a reorientation would be beneficial for many domains of engineering practice, but it is absolutely necessary if engineering is to take seriously social injustices and their underlying causes, including those of the sort identified in Grand Challenges.

Better integration of the social and technical facets of engineering is one way to improve grandchallenge problem solving, but engineers might also bring themselves more fully into traditionally "non-engineering" domains as well. For example, engineers need not assume policy-making is external to their work, but instead might take an active role in engineering-related policy making, analyzing the public gains and losses of their projects, collaborating with a range of stakeholders in

15 Thomas Hughes (1983) has famously applied such an approach in analyzing the historical development of electric power systems in the United States. 
establishing promising policy directions, and otherwise providing input to the political process. Grand Challenges laments the existence of not-always-favorable political environments, implying engineers' involvement in politics and policy making is a necessary evil. The Engineer of 2020, on the other hand, sees politics as part and parcel of engineering. As the report suggests, "the engineers of 2020 will be actively involved in political and community arenas" (NAE, 2004, p. 44). While not sole crusaders speaking "truth to power," responsibilities for mobilizing political interests and building the political resolve needed to advance socially beneficial engineering projects fall on engineers as much as anyone. So too do responsibilities for the negative consequences of technology (that is, sociotechnical) innovation. Hence, engineering should be held accountable for devising precautionary measures with both technical and political components.

As with politics, engineering would be better situated to address grand-challenge problems if engineers did not take as "given" or fixed the apparent public demand for particular engineering solutions. What is demanded by consumers and society-as well as what is understood to be desirable, or even viable-is contingent on a range of factors, some of which engineers could take responsibility for redirecting. Grand Challenges offers a glimpse at such a strategy by advocating systems "designed to be compatible with human users," but then reveals the ultimate goal of this approach is "ensuring user cooperation with new technology" (NAE, 2008, p. 5). A more productive approach to the user-technology relationship would be to ensure new technologies cooperate with their users or, more precisely, that new technologies are perceived to be worthy of accommodation by users and not imposed upon them. For example, rather than forcing teachers to "revamp their curricula and teaching styles to benefit from electronic methods of personalized learning" (as quoted above), personalized learning technologies should be developed and deployed in ways that integrate with existing curricula and pedagogies, both of which have been refined over millennia and which form the foundation of teachers' expertise. Ignoring that foundation, and placing the burden of accommodation on teachers, follows a logic of "technology fix" in education that harkens back to well-documented failures of information-technology-driven educational reforms of the 1980s and 1990s (Pflaum, 2004).

In this reframing, the onus is placed on the designers of the new technologies that are inserted into people's lives, rather than the other way around. This does not mean that user-resistance should halt promising new initiatives, but that such initiatives need to be made more salable to their intended audiences - and engineers share responsibility for making this happen. Extending this line of reasoning, engineers might do better in addressing grand-challenge problems by questioning existing market demand as the final arbiter of which projects get done. Instead, engineers could take market conditions as part of their domain of influence-not only identifying market opportunities and constraints and accepting them as fixed, but leveraging alternative institutions (e.g., politics, the media, education, and marketing) where existing market demand is inadequate. Consumer product innovators redirect market demand continually; grand-challenge problem solvers ought to consider the same. Recognizing limitations of the market in directing technology development toward social-problem solving is central to reconfiguring engineering in a way that makes it more responsive to social injustices.

\section{A Multiple-Stakeholders Model of Collaboration}

Determining new roles for engineers in the future relies on serious and sustained communication between engineering and non-engineering groups. Again, this is explicitly recognized by The Engineer of 2020, which notes "it is important to engage all segments of the population in a vigorous discussion of the roles of engineers and engineering and to establish high aspirations for engineers that reflect a shared vision of the future" (NAE, 2004, p. 48). It is untenable to assume engineers can 
or should develop technological solutions to social problems independently of professionals and social groups with other expertise and perspectives. Real-world problems know no disciplinary boundaries: technical, financial, political, and cultural components intertwine. While professional grandstanding may serve in a limited way to advance engineering's public image, romanticizing engineering as the "driver of civilization" probably undermines its credibility among thoughtful observers. Instead of defining themselves as apart from (and by implication above) other professional groups, engineers would do better to articulate a future for the profession that prioritizes collaboration with social/professional groups beyond research scientists-policy makers, business leaders, social scientists, humanists, users, and a wide range of others.

Our proposed model of collaboration does not entail engineers merely departing their knowledge to others-providing the technical input upon which others will draw. It requires engineers to reformulate their role in response to dynamic, sometimes unpredictable, interdisciplinary problemsolving contexts. The Engineer of 2020 recognizes that to "build a clear image of [their] new roles," engineers will have to "accommodate innovative developments from nonengineering fields" (NAE, 2004, p. 5). That means "engineering" itself should be open to change through the process of interdisciplinary collaboration with other professional groups. This approach applies equally to engineering's relationship to the larger public, which again diverges from what is evident in Grand Challenges. The Engineer of 2020 identifies "excellence in communication (with technical and public audiences)" as "essential attributes" for future engineers (p. 35). Effective communication skills are surely needed to better educate the public concerning engineering principles and possibilities, but good communication is always a two-way street: Engineers should conceive of the public in a way that offers potential for learning and not only teaching (or preaching) about what engineering has to offer. ${ }^{16,17}$

\section{Engineering, Warts and All}

As mentioned above, Grand Challenges fails to acknowledge engineering's responsibility for contributing to grand-challenge-type problems, and it does so in two ways. First, the report attributes the causes of grand-challenge problems to non-technical factors, keeping silent about the roles played by technologies in creating or exacerbating the problems. Second, because the report implies engineering is responsible only for the technical dimensions of technology making, it immunizes engineers from accountability for the non-technical causes of grand-challenge problems, even where technologies enable or exacerbate these causes. This logic parallels the decontextualized view of technology—and by implication engineers-as neutral participants in problem solving. Taken at face value, such a view would logically prevent engineers from assuming any significant role in social problem solving, since the non-technical dimensions that direct (neutral) engineering would necessarily be rendered irrelevant to how engineering was applied. Only by reversing this logic-and reflecting on engineering's liabilities in producing sociotechnical challenges-can engineering be cast in a way that is more than tangentially relevant to the tackling of these challenges.

\footnotetext{
16 A third NAE report, Educating the Engineer of 2020, falls short of our suggestion that collaboration is a twoway street. As with Grand Challenges, Educating the Engineer implies that the primary goal of engineers improving communication with the public is "enhancing public awareness of engineering" (NAE, 2005, 27).

17 A vast body of literature in "public understanding of science" - and a journal by the same name-has developed over the past three decades. This literature emphasizes the embedded intelligence of local communities' knowledge systems, working as they do from different perspectives and responding to different sets of variables and assumptions than outside experts.
} 
Unlike Grand Challenges, The Engineer of 2020 frankly admits that, in addition to its benefits, "there have also been negative results of technology" (NAE, 2004, p. 48). That recognition directs attention to the question, "How can engineers best be educated to be leaders, able to balance the gains afforded by new technologies with the vulnerabilities created by their byproducts without compromising the well-being of society and humanity?" (p. 2). ${ }^{18}$ However unlikely it may be that the authors of Grand Challenges would disagree with such a statement, the report nevertheless systematically avoids recognition of any such tradeoffs surrounding technology or, for that matter, engineering. In our assessment, taking responsibility for negative consequences caused by prior technologies does not harm engineering's credibility. To the contrary, recognizing the mixed consequences of technological endeavors benefits the profession by helping to set more realistic goals when addressing complex problems and by reminding engineers (and others) of the need for caution, precautions, and humility.

\section{CONCLUSION}

We share the enthusiasm of many engineers and engineering educators in redirecting engineering energies toward grand-challenge problems. But we also see these problems as an opportunity to rethink the nature of engineering and recast the relationship between engineering and society in a way more likely to respond effectively to social injustices. A textual analysis of the Grand Challenges for Engineering report shows that it advances a problematic and increasingly outdated image of engineering as separated from other domains of social practice and innovation. This paper has identified several of the assumptions underlying that image and described how they are untenable in understanding engineering generally, but are especially problematic if we are systematically to redirect engineering toward complex social problem solving in ways that enhance social justice. We have also identified how the technical-social dichotomy, in concert with externalization of responsibility for understanding social dimensions of technology, has problematic implications for engineers' collaboration with non-technical participants in social problem solving. Drawing examples from The Engineer of 2020, we proposed alternative understandings of engineering and its proper role in identifying and solving sociotechnical problems.

\section{ACKNOWLEDGEMENTS}

The authors would like to thank all those who provided feedback on various iterations of this article, including the editors of IJESJP, two anonymous reviewers, and co-presenters and participants in the 2011 ASEE conference session, "Ethical Perspectives on the Grand Challenges."

\section{REFERENCES}

Akin, W. E. (1977). Technocracy and the American dream: The technocrat movement, 1900-1941. Berkeley: University of California Press.

Baillie, C. (2006). Engineers within a local and global society. San Rafael, CA: Morgan \& Claypool.

Baxter Magolda, M. B. (1992). Knowing and reasoning in college: Gender-related patterns in students' intellectual development. San Francisco, CA: Jossey-Bass.

Belenky, M. F., Clinchy, B. M., Goldberger, N. R., \& Tarule, J. M. (1986). Women's ways of knowing: The development of self, voice, and mind. New York, NY: Basic Books.

18 The implications of our analysis for engineering education are immense, spanning everything from curriculum design and accreditation practices to educational cultures in engineering to strategies for attracting prospective students into engineering programs. While beyond the scope of the present paper, this domain deserves systematic attention on its own, especially given the extent to which the Grand Challenges report and approach have been adopted by engineering programs. 
Catalano, G. D. (2007). Engineering, poverty, and the earth. San Rafael, CA: Morgan \& Claypool.

Cech, E. A., \& Waidzunas, T. J. (2011). Navigating the heteronormativity of engineering: The experiences of lesbian, gay, and bisexual students. Engineering Studies, 3(1), 1-24.

Downey, G. L. (2009). What is Engineering Studies for? Dominant practices and scalable scholarship. Engineering Studies, 1(1), 55-76.

Faulkner, W. (2000). Dualism, hierarchies and gender in engineering. Social Studies of Science, 30(5), 759792.

Freire, P. (1996). Pedagogy of the oppressed (2nd ed.). New York, NY: Penguin.

Geiryn, T. F. (1983). Boundary-work and the demarcation of science from non-science: Strains and interests in professional ideologies of scientists. American Sociological Review, 48(6), 781-795.

Gopakumar, G. (2010). Transforming water supply regimes in India: Do public-private partnerships have a role to play? Water Alternatives. 3(3), 492-511.

Hofer, B. K., \& Pintrich, P. R. (Eds.). (2002). Personal epistemology: The psychology of beliefs about knowledge and knowing. Mahwah, NJ: Lawrence Erlbaum.

Hughes, T. P. (1983). Networks of power: Electrification in western society, 1880-1930. Baltimore, MD: Johns Hopkins University Press.

Jamison, A., Christensen, S. H., \& Botin, L. (2011). A hybrid imagination: Science and technology in cultural perspective. San Rafael, CA: Morgan \& Claypool.

King, P. M., \& Kitchener, K. S. (1994). Developing reflective judgment: Understanding and promoting intellectual growth and critical thinking in adolescents and adults. San Francisco, CA: Jossey-Bass.

Kline, R. (1995). Construing "technology" as "applied science": Public rhetoric of scientists and engineers in the United States, 1880-1945. Isis, 86(2), 194-221.

Lagesen, V. A., \& Sørensen, K. H. (2009). Walking the line? The enactment of the social/technical binary in software engineering. Engineering Studies, 1(2), 129-149.

Layton, P. E. (1986). The revolt of the engineers: Social responsibility and the American engineering profession. Baltimore, MD: Johns Hopkins University Press.

Leydens, J. A., Lucena, J. C., \& Schneider, J. (2012). Are engineering and social justice (in)commensurable? A theoretical exploration of macro-sociological frameworks. International Journal of Engineering, Social Justice, and Peace. 1(1), 63-82.

Lindblom, C. E., \& Woodhouse, E. J. (1993). The policy-making process (3rd ed.). Englewood Cliffs, NJ: Prentice Hall.

Manning, P. K., \& Cullum-Swan, B. (1994). Narrative, content, and semiotic analysis. In N. K. Denzin \& Y. S. Lincoln (Eds.), Handbook of qualitative research (463-477) Thousand Oaks, CA: Sage.

National Academy of Engineering. (2004). The engineer of 2020: Visions of engineering in the new century. Washington, DC: National Academies Press.

National Academy of Engineering. (2005). Educating the engineer of 2020: Adapting engineering education to the new century. Washington, DC: National Academies Press.

National Academy of Engineering. (2008). Grand challenges for engineering. Washington, DC: National Academies Press. Retrieved from http://www.engineeringchallenges.org/?ID=11574

Perry, W. G. (1970). Forms of intellectual and ethical development in the college years: A scheme. New York, NY: Holt, Rinehart \& Winston.

Pflaum, W. D. (2004). The technology fix: The promise and reality of computers in our schools. Alexandria, VA: Association for Supervision and Curriculum Development.

Pitt, J. C. (1999). Thinking about technology: Foundations of the philosophy of technology. New York, NY: Seven Bridges Press.

Riley, D. (2008). Engineering and social justice. San Rafael, CA: Morgan \& Claypool.

Sharpe, J. P., Petti, D. A., \& Bartels, H. W. (2002). A review of dust in fusion devices: Implications for safety and operational performance. Fusion Engineering and Design, 63-64, 153-163. 
Veblen, T. (1921). The engineers and the price system. New York, NY: B. W. Huebsch.

Vincenti, W. G. (1990). What engineers know and how they know it: Analytical studies from aeronautical history. Baltimore, MD: Johns Hopkins University Press.

Winner, L. (1988). Do artifacts have politics? In The whale and the reactor: A search for limits in an age of high technology. Chicago, IL: University of Chicago Press, 19-39.

Winter, J. (2000). Dust: A new challenge in nuclear fusion research? Physics of Plasmas, 7(10), 3862-3866.

Woodhouse, E. J., \& Nieusma, D. (2001). Democratic expertise: Integrating knowledge, power, and participation. In M. Hisschemöller, R. Hoppe, W. N. Dunn, \& J. R. Ravetz (Eds.), Knowledge, power, and participation in environmental policy analysis (73-96). New Brunswick, NJ: Transaction Publishers. 